\title{
The influence of resin composite with high fiber aspect ratio on fracture resistance of severely damaged bovine incisors
}

\author{
Lippo LASSILA ${ }^{1}$, Viivi OKSANEN ${ }^{1}$, Márk FRÁTER ${ }^{2}$, Pekka K.VALLITTU ${ }^{1,3}$ and Sufyan GAROUSHI ${ }^{1}$ \\ ${ }^{1}$ Department of Biomaterials Science and Turku Clinical Biomaterials Center-TCBC Institute of Dentistry, University of Turku, Finland \\ ${ }^{2}$ Department of Operative and Esthetic Dentistry, Faculty of Dentistry, University of Szeged, Szeged, Hungary \\ ${ }^{3}$ City of Turku Welfare Division, Oral Health Care, Turku, Finland \\ Corresponding author, Sufyan GAROUSHI; E-mail: sufgar@utu.fi
}

\begin{abstract}
The aim was to determine the fracture-behavior of incisors restored with different post-core foundations and crown made of conventional composite (PFC, G-aenial Anterior). Forty bovine-incisors were cut and divided into 5 groups. Group A had teeth restored using fiber-post and Gradia Core as core build-up and crown of PFC. Group B contained teeth restored with fiber-post and core made of everX Flow and crown of PFC. In Group C, the teeth were restored with everX Flow as post-core and crown of PFC. Group D, postcore-crown restorations were indirectly made from CERASMART. Group E, teeth were restored with Gradia Core as post-core and crown of PFC. Restored teeth were statically-loaded until fracture. ANOVA revealed that restoration technique significantly affected load-bearing capacity $(p<0.05)$. Restored incisors (Group B) had the highest load-bearing capacity (443 N) among all groups. Using everX Flow as core material with fiber-post is promising to strengthen structurally compromised incisors.
\end{abstract}

Keywords: Load-bearing capacity, Fiber composite, Anterior crown, EverX Flow

\section{INTRODUCTION}

Endodontically treated teeth often require substantial build-up with varying post-core foundation materials to retain a complete crown restoration. In recent years various types of fiber-reinforced composite (FRC) posts have been introduced in order to provide the dental profession an alternative to cast or prefabricated metal posts for restoring endodontically treated teeth, as the elastic moduli of these fiber posts are closer to that of dentine than that of metal posts ${ }^{1)}$. In restoring severely damaged dentition, it is important to restore strategically important teeth even though they may be severely damaged. By using adhesive techniques and particulate filler composite ( $\mathrm{PFC}$ ), as both core and veneering material, root filled teeth can in some instances be restored without conventional crown coverage $^{2)}$. A complete crown with a $2 \mathrm{~mm}$ ferrule on a sound tooth structure changed the distribution of forces to the root and the post-core complex ${ }^{3)}$. One previous study reported that when bonded composite was used on structurally weakened roots, there was no statistical difference in strength between post-core restorations that used a ferrule and those without a ferrule ${ }^{4)}$. Many studies on the mechanical strength of pulpless incisors restored with fiber posts and PFC cores have shown lower incidences of root fractures in comparison with other types of postcore systems ${ }^{5-7)}$. Although some clinical reports suggest that $\mathrm{PFC}$ core is a promising alternative to conventional treatment modalities ${ }^{2,8}$, fracture of the composite core has also been reported as a reason for failure ${ }^{9,10)}$. Due to failures of this type, using restorative composites

Color figures can be viewed in the online issue, which is available at J-STAGE.

Received Feb 22, 2019: Accepted May 13, 2019

doi:10.4012/dmj.2019-051 JOI JST.JSTAGE/dmj/2019-051 in large high-stress bearing applications such as core structure remains controversial. The relatively high brittleness and low fracture toughness of current core composites still restrict their use in these large stressbearing foundations $\mathbf{s}^{11,12}$.

The requirement to strengthen composite has led to an ever increasing research effort into reinforcement techniques. Several former approaches dealt with incorporation of ceramic particle reinforced (random orientation), whisker (single or multi-layer) or fiberreinforced (long or short fibers in various orientations) $)^{13-15}$. A number of manufacturers have developed short fiberreinforced composites (SFRCs) which claimed to overcome the weakness of conventional PFC. These SFRCs are interesting materials because of their close resemblance to dentine at the level of microstructure and mechanical properties and some of them are recommended to use as bulk base or core build-up materials in large cavities of either vital or non-vital teeth ${ }^{16-19)}$.

Previous studies by Garoushi and co-workers found that the restoration of anterior endodontically treated teeth with SFRC yielded a better load-bearing capacity as opposed to the application of FRC post ${ }^{20,21}$. This was partly confirmed by Forster et al., and Fráter et al., in endodontically treated premolar teeth with class I cavity. In those studies, the directly layered SFRC post and core groups displayed promising performance in matter of fracture behavior ${ }^{22,23)}$.

New formulations of flowable SFRC (everX Flow) with high fiber aspect ratio (micrometer scale) and isotropic reinforcement effect was launched globally in 2019. The effectiveness of fiber reinforcement is strongly dependent on microstructural parameters such as resin matrix, fiber diameter, fiber length, fiber orientation 
and fiber loading ${ }^{18,24)}$. Based on this knowledge, it can be assumed that SFRC (with high fiber aspect ratio) could sustain the loads required for complete anterior crown restorations. Thus, the first aim of this study was to investigate the load-bearing capacity and failure mode of post-core restorations made of flowable SFRC. The second aim was to investigate the curing performance assessed by surface microhardness at different depths within the root canal for each used composite. The null hypotheses were that (1) the incisors restored with the tested restorative techniques would show similar load bearing capacity, and that (2) the failure mode would not depend on the applied restorative technique.

\section{MATERIALS AND METHODS}

All materials used in this study were listed in Table 1.

Totally 40 intact and caries-free bovine incisors were used. All teeth were prepared by the same trained operator. The clinical crowns were removed from the CEJ using 1000-grit (FEPA) silicon carbide abrasive paper at $300 \mathrm{rpm}$ under water cooling using an automatic grinding machine (Struers Rotopol-11, Struers, Copenhagen, Denmark). The pulp and periodontal tissue were removed and cleaned. Then the root length was adjusted to $15 \mathrm{~mm}$ from the root apex. After that, root was embedded in plastic tube with acrylic resin except for $2 \mathrm{~mm}$ of the cervical area (Fig. 1). Next, they were divided into 5 groups ( $n=8 /$ group) and stored in water until further processing. The mean of root diameter (SD) is $7.18(0.4) \mathrm{mm}$ and that of root canal diameter is $2.37(0.33) \mathrm{mm}$. There were no significant differences in the each diameter of root and root canals. Post space preparations were made with post drills (Parapost stainless drills, Coltène/Whaledent, Mahwah, NJ, USA) using low speed hand piece under water cooling. Postcore and composite crowns were fabricated according to the groups they belonged (Fig. 2).

\section{Post and core fabrication}

The coronal surface of the teeth was etched for $20 \mathrm{~s}$ using a 37\% phosphoric acid etch-gel (Scotchbond, 3M ESPE, St. Paul, MN, USA), rinsed and gently air-dried. Dentine adhesive were applied according to the manufacturer's instructions (Scotchbond Universal, 3M ESPE).

For Groups A (control) and B, dual-cure self-adhesive luting material (G-CEM LinkAce) was mixed according to manufacturer's instruction, and delivered it into root canal using automix tips. Prefabricated $(\varnothing 1.6 \mathrm{~mm})$ glass fiber post (MI Core Fiber Post, GC, Tokyo, Japan) after surface treatment with a primer (G-Multi Primer, GC) was slowly inserted into luting-filled root canal. After the post reached at the regulated length $(10 \mathrm{~mm})$, excess luting material removed at level of sectioning. The cement was light cured for at least $40 \mathrm{~s}$ (Elipar TM S10, 3M ESPE, Landsberg am Lech, Germany) in $45^{\circ}$ angle, close to the root of the post. The wavelength of the light was between 430 and $480 \mathrm{~nm}$ and light intensity was $1,600 \mathrm{~mW} / \mathrm{cm}^{2}$. The posts were extending $4 \mathrm{~mm}$ above the coronal surface of the prepared teeth. Composite cores (Group A: CBC, Gradia Core \& Group B: SFRC, everX Flow, fiber length $100-300 \mu \mathrm{m} \& \varnothing 6 \mu \mathrm{m}$ ) extending 5.5 $\mathrm{mm}$ incisal to the sectioned tooth surfaces were build-up and polymerized incrementally (20 s per layer), thus the post will be covered with the core build-up material.

For Group C, posts and cores were fabricated from

Table 1 Materials used in the study

\begin{tabular}{|c|c|c|c|}
\hline Brand (code) & Manufacturer & Type & Composition \\
\hline $\begin{array}{l}\text { G-aenial } \\
\text { Anterior } \\
(\mathrm{PFC})\end{array}$ & $\begin{array}{l}\text { GC, } \\
\text { Tokyo, Japan }\end{array}$ & $\begin{array}{l}\text { Hybrid microfilled } \\
\text { composite }\end{array}$ & $\begin{array}{l}\text { UDMA, dimethacrylate co-monomers, prepolymrized silica } \\
\text { and strontium fluoride containing fillers } 76 \mathrm{wt} \%\end{array}$ \\
\hline $\begin{array}{l}\text { everX Flow } \\
(\text { SFRC) }\end{array}$ & $\mathrm{GC}$ & $\begin{array}{l}\text { Flowable fiber } \\
\text { reinforced composite } \\
\text { (bulk shade) }\end{array}$ & $\begin{array}{l}\text { Bis-EMA, TEGDMA, UDMA, micrometer scale } \\
\text { glass fiber filler (100-300 } \mu \mathrm{m} \& \varnothing 7 \mu \mathrm{m}) \\
\text { Barium glass } 70 \mathrm{wt} \%, 46 \mathrm{vol} \%\end{array}$ \\
\hline $\begin{array}{l}\text { Gradia Core } \\
(\mathrm{CBC})\end{array}$ & $\mathrm{GC}$ & $\begin{array}{l}\text { Dual-cured core } \\
\text { build-up composite }\end{array}$ & $\begin{array}{l}\text { Methacrylic acid ester } 20-30 \mathrm{wt} \% \text {, fluoro-alumino-silicate } \\
\text { glass } 70-75 \mathrm{wt} \% \text {, silicon dioxide } 1-5 \mathrm{wt} \% \text {. }\end{array}$ \\
\hline Cerasmart & GC & CAD/CAM block & $\begin{array}{l}\text { Bis-MEPP, UDMA, dimethacrylate co-monomers, } \\
\text { silica and barium nano glass } 71 \mathrm{wt} \%\end{array}$ \\
\hline $\begin{array}{l}\text { G-CEM } \\
\text { LinkAce }\end{array}$ & $\mathrm{GC}$ & $\begin{array}{l}\text { Dual-cured, self- } \\
\text { adhesive cement }\end{array}$ & $\begin{array}{l}\text { Paste A: fluoroalumino silicate glass, initiator, UDMA, } \\
\text { dimethacrylate, silicon dioxide Paste B: silicon dioxide, } \\
\text { UDMA, dimethacrylate, initiator, inhibitor }\end{array}$ \\
\hline $\begin{array}{l}\text { MI Core } \\
\text { Fiber Post }\end{array}$ & $\mathrm{GC}$ & Regular fiber post & UDMA, PMMA, glass fibers \\
\hline
\end{tabular}

UDMA, urethane dimethacrylate; TEGDMA, triethyleneglycol dimethacrylate; Bis-EMA, Ethoxylated bisphenol-Adimethacrylate; Bis-MEPP, 2,2-bis(4 methacryloxypolyethoxyphenyl) propane; PMMA, polymethyl methacrylate; wt\%, weight percentage. 


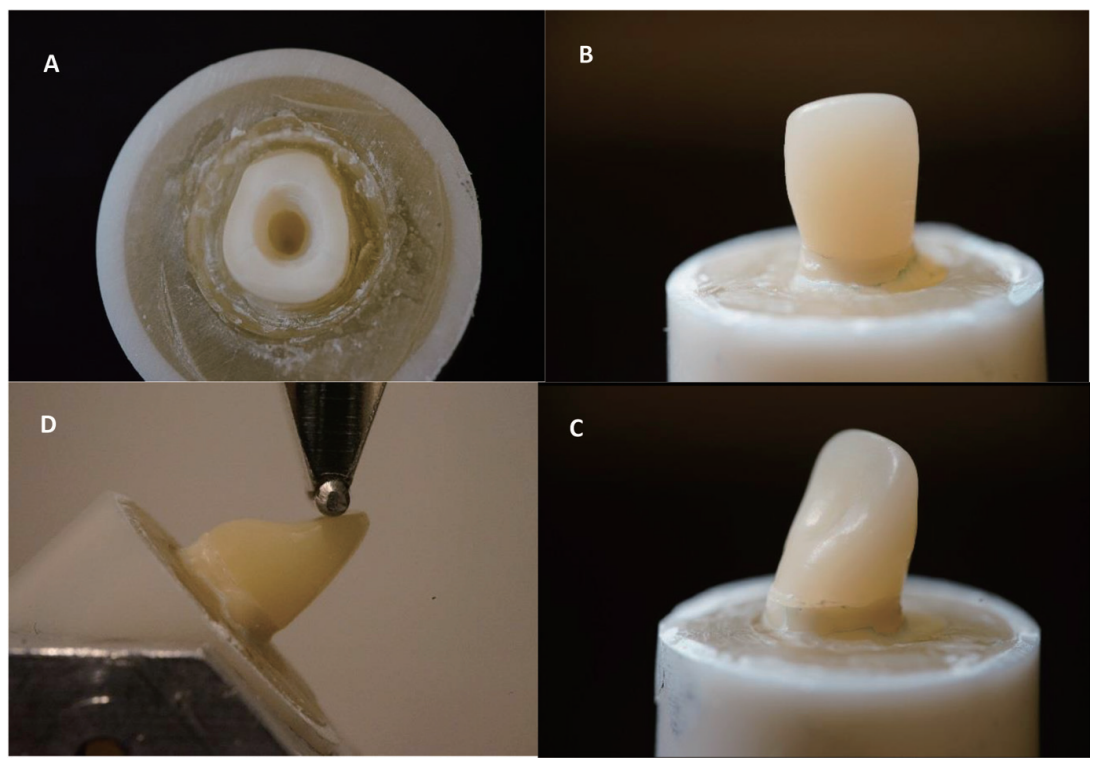

Fig. 1 A photograph showing test specimen before (A) and after restoration (B and C) and the static load test setup (D).
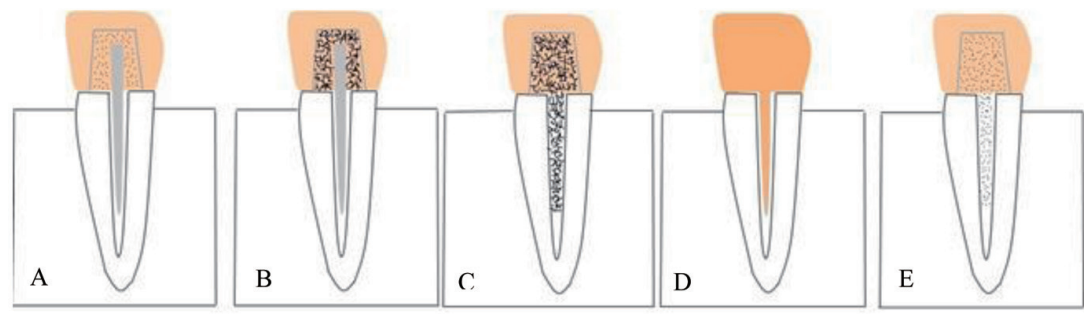

Fig. 2 Schematic figure representing the test groups with different post-core foundations.

Group A: fiber-post and Gradia Core as core build-up and crown of PFC. Group B: fiber-post and core made of everX Flow and crown of PFC. Group C: everX Flow as post-core and crown of PFC. Group D: postcore-crown made from Cerasmart. Group E: Gradia Core as post-core and crown of PFC.

SFRC (everX Flow). Posts were made by applying and polymerizing the SFRC into the prepared canals in bulk and cores were fabricated and polymerized as described previously.

For Group D, a photoimpression was taken of the post-core-crown model using dental $\mathrm{CAD} / \mathrm{CAM}$ device (CEREC, Sirona Dental Systems, Long Island City, NY, USA). A single-structure of post-core-crown restorations were indirectly made from $\mathrm{CAD} / \mathrm{CAM}$ composite block (Cerasmart) and cemented using dual-cure self-adhesive luting material (G-CEM LinkAce).

For Group E, posts and cores were fabricated from CBC (Gradia Core). Posts were made by applying and polymerizing the $\mathrm{CBC}$ into the prepared canals in bulk and cores were fabricated and polymerized as described previously.

In order to have the same core dimensions, transparent template matrix (Memosil 2, Heraeus
Kulzer, Hanau, Germany) of well-constructed core was used to aid core fabrication.

\section{Crown fabrication}

Crown fabrication was designed in order to simulate chair-side fabricated technique with light-cured PFC (G-aenial Anterior) except for Group D. In order to minimize variations in specimens, a transparent template matrix of an ideally contoured crown was used to aid crown fabrication. Fabricated mold of crown was filled with PFC, then press and place it over the build-up core, and light cured from outside. The light source was placed in close contact $(1-2 \mathrm{~mm})$ with crown surface. After polymerization, crown mold was removed. Prior to the incline-loading test, excess composite around the cervical area was removed and polished using abrasive polishing points (Jiffy Polishers, Ultradent, South Jordan, UT, USA) so that the margin of root and crown material 
appeared clearly (Fig. 1). All fabricated specimens were stored in distilled water at room temperature for $48 \mathrm{~h}$.

\section{Fracture load test}

A static load was applied to the restored teeth with a universal testing machine (Lloyd model LRX, Lloyd Instruments, Fareham, UK) at a speed of $1 \mathrm{~mm} / \mathrm{min}$. The acrylic block containing the restored tooth was tightly fixed to the inclined metal base to provide a 45-degree angle between the palatal surface of the incisal edge and the loading tip (spherical Ø $2 \mathrm{~mm}$ ) (Fig. 1). The loading event was registered until fracture for each restored tooth and the fracture patterns for each specimen was visually analyzed by two investigators and categorized to 3 typical types of failures.

\section{Microhardness test}

Restored teeth $(n=3)$ from Groups (C and E) were sectioned mid-sagitally in the mesio-distal plane using a ceramic cutting disc operating at a speed of $100 \mathrm{rpm}$ (Secotom-50, Struers) under water cooling. Then, sectioned tooth was gently polish using \#4000-grit silicon carbide papers at 300 rpm under water cooling using an automatic grinding machine (Rotopol-1, Struers). Surface microhardness (VH) of composites (SFRC and CBC) inside the canal was measured using a Vickers indenter (Duramin 40, Struers) with a 40 objective lens and a load of $1.96 \mathrm{~N}$ applied for $15 \mathrm{~s}$. Each tested sectioned restoration $(n=3)$ was subjected to 6 indentations, starting from the top (coronal part, $0 \mathrm{~mm}$ ) and moving on each $2 \mathrm{~mm}$ towards the bottom (apical part, $10 \mathrm{~mm}$ ) of the canal. The diagonal length impressions were measured and Vickers values were converted into microhardness values by the machine. Surface microhardness was obtained using the following equation:

$$
\mathrm{VH}=\frac{1854.4 \times P}{d^{2}}
$$

where $\mathrm{VH}$ is Vickers hardness in $\mathrm{kg} / \mathrm{mm}^{2}, P$ is the load in grams and $d$ is the length of the diagonals in $\mu \mathrm{m}$.

\section{Statistical analysis}

The data were statistically analyzed with SPSS software (SPSS ver. 23, IBM, Somers, NJ, USA) using one-way analysis of variance (ANOVA) at the $p<0.05$ significance level followed by a Levene's test of equality and Tukey HSD post hoc test to determine the differences between the groups.

\section{RESULTS}

The load-bearing capacity of the teeth restored with different techniques is shown in Fig. 3. ANOVA revealed that the restoration technique significantly affected load-bearing capacity $(p<0.05)$, however, some interaction existed between the groups. Levene's test of equality of error variances confirmed that test is valid with $p=0.312$.

Restored incisors (Group B) had the highest load- bearing capacity $(443 \pm 143 \mathrm{~N})$ among all the groups tested. ANOVA showed that restorations reinforced by post and core made of SFRC (Group C) had a statistically significantly higher load-bearing capacity $(300 \pm 98 \mathrm{~N})$ than incisors restored with CBC as post and core (Group $\mathrm{E}, 153 \pm 55 \mathrm{~N})(p<0.05)$. Whereas restorations made from plain CAD/CAM composite (Group D) gave higher load values $(236 \pm 89 \mathrm{~N})$ than those with plain CBC (Group E) $(p>0.05)$.

The data showed that crowns additionally reinforced with fiber post (Groups A and B), have higher loadbearing capacity $(p<0.05)$ than crowns without fiber post (Groups E and C) respectively.

Visual inspection revealed three types of fracture patterns (Figs. 4 and 5) according to the materials used: debonding of crowns without tooth fracture was the main type and found in all groups, debonding with tooth fracture was found only in groups without fiber post (Groups C, D, E), and delamination of surface PFC from underlying SFRC core in crowns additionally reinforced with fiber post (Group B).

The surface microhardness $(\mathrm{VH})$ of the composite core materials (CBC and SFRC) decreased gradually within a limited range with increasing depth (Fig. 6).

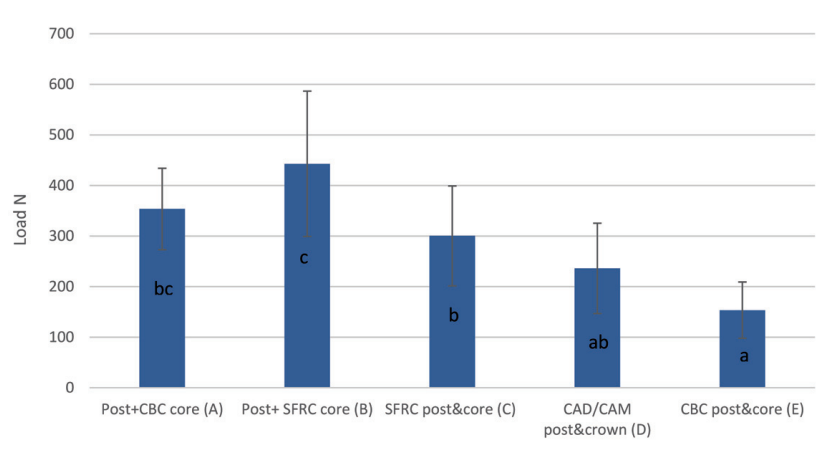

Fig. 3 Mean values of load-bearing capacity $(\mathrm{N})$ and standard deviation (SD) of tested groups.

The same letters inside the bars represent nonstatistically significant differences $(p>0.05)$ among the groups.

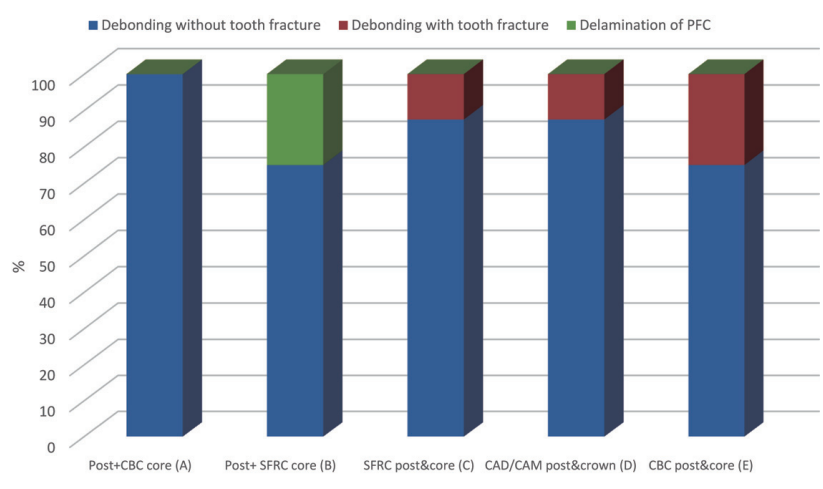

Fig. 4 Percentage of various fracture patterns of the test specimens. 

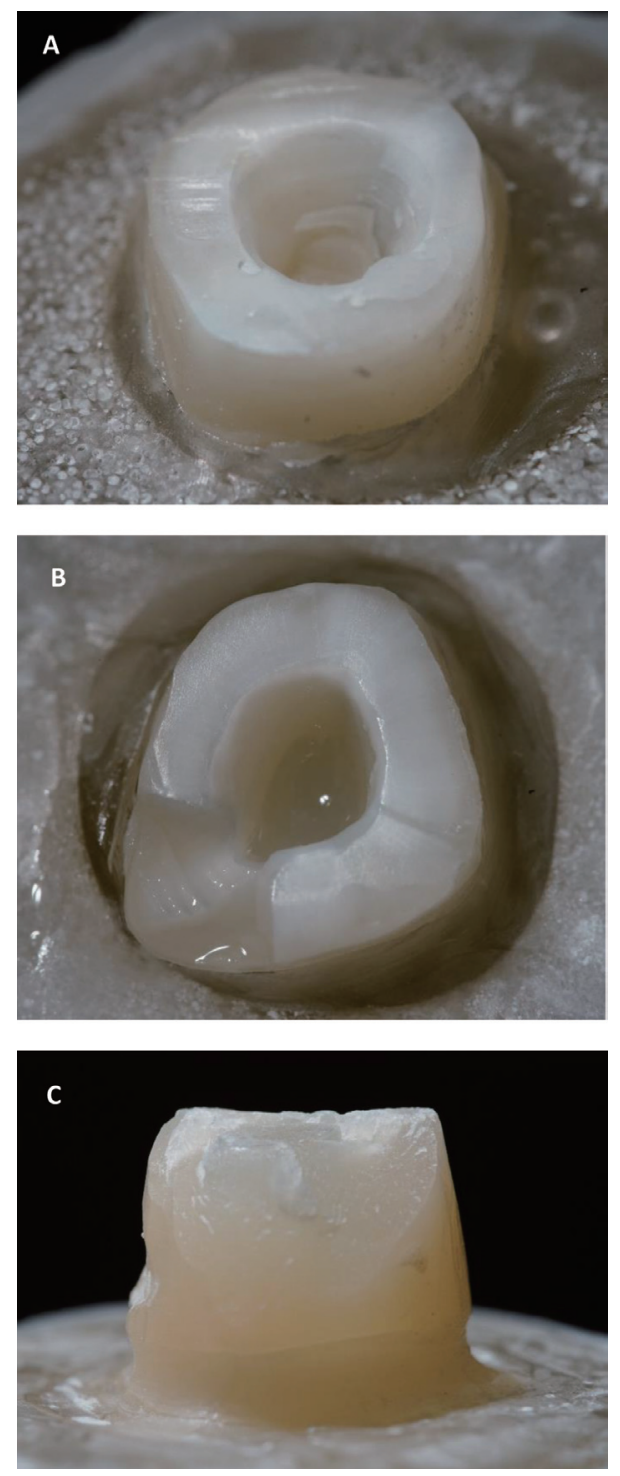

Fig. 5 (A) Debonding without tooth fracture; (B) Debonding with tooth fracture; (C) Delamination of PFC.

Data showed no difference in $\mathrm{VH}$ values between the tested core composites at $6 \mathrm{~mm}$ depth. However, after 6 $\mathrm{mm}$ SFRC presented the most drastic decrease along the $\mathrm{VH}$ values. There was a significance difference between the surface microhardness of SFRC measured at 8 and $10 \mathrm{~mm}$ depth in the root canal but not for CBC (Fig. 6).

\section{DISCUSSION}

The crown restorations in this study were designed to evaluate the failure mode and load-bearing capacity of incisors restored with biomimetic approach for the fabrication of direct composite crown. This design reproduced the scenario of major loss of tooth structure.

In this series an attempt was made by using flowable SFRC as core material with or without prefabricated

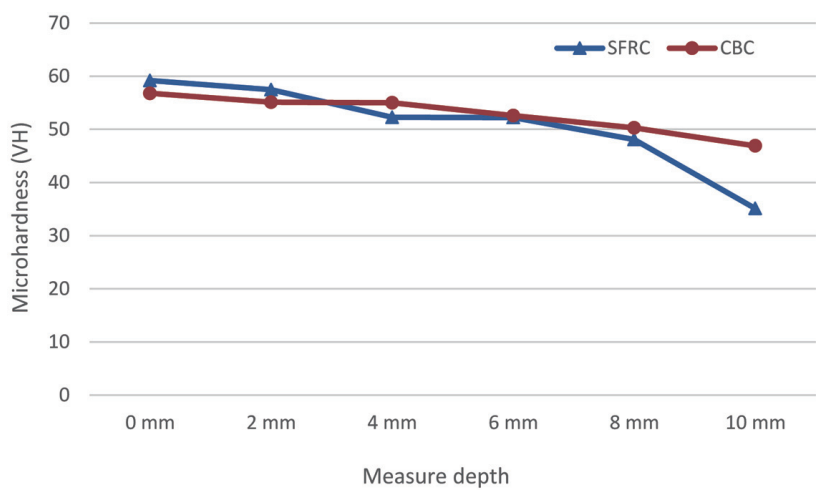

Fig. 6 Surface microhardness (VH) mean values of tested flowable core materials at different depths inside the root canal.

glass fiber post under surface layer of $\mathrm{PFC}$, i.e. biomimetic composite restorations, in order to emulate a more natural fracture behavior of composite restorations. The new micrometer scale SFRC (everX Flow) used in this study has previously been reported to exhibit high fracture toughness and flexural strength ${ }^{18,25)}$. To our knowledge there are no other dental composites with fracture toughness values above $2.6 \mathrm{MPa} \mathrm{m}{ }^{1 / 2}$. Thus, we assumed that flowable SFRC core could sustain the loads required for complete anterior crown restorations. The results of the fracture test support our assumption because SFRC core restorations (Groups B and C) showed a substantial improvement in load-bearing capacity and failure mode when compared with conventional direct CBC core restorations (Groups A and E) and indirect composite restoration (Group D).

Data available in the literature regarding fracture toughness values of different conventional (direct/ indirect) (light/dual-cured) composites are in range of 1.1 to $1.8 \mathrm{MPa} \mathrm{m}{ }^{1 / 2}$ which are inferior values in comparisons with SFRC $^{26,27)}$.

Short fibers enhanced the ability of the material to resist the crack propagation, as well as to reduce the stress intensity at the crack tip from which a crack propagates in an unstable manner. As a consequence, an increased fracture toughness can be expected. A recent systematic review by Heintze et al., showed that fracture toughness being mostly correlated with clinical fracture of dental composites and no correlations were observed between clinical outcomes and flexural modulus or flexural strength of these materials ${ }^{28}$. Furthermore, several in vitro studies have revealed a strong correlation between fracture toughness of a material and fracture behavior of the corresponding dental restoration. In particular for biomimetic or bilayered restorations made of a dentine-replacing SFRC core and an enamel-replacing PFC veneer a more nature-like fracture behavior and fewer catastrophic failures were observed if the SFRC had a more dentine-like fracture toughness ${ }^{29-36)}$.

Aspect ratio, critical fiber length, fiber loading and 
fiber orientation are the main factors that could improve or impair the mechanical properties of SFRC ${ }^{24)}$. Aspect ratio is the fiber length to fiber diameter ratio $(1 / d)$. It affects the tensile strength, flexural modulus and the reinforcing efficiency of the $\mathrm{FRC}^{24)}$. Microfibers used in this study have aspect ratio of more than 30 . In order for a fiber to act as an effective reinforcement for polymers, stress transfer from the polymer matrix to the fibers is essential $^{37)}$. This is achieved by having a fiber length equal to or greater than the critical fiber length and the given fiber aspect ratio in range of 30-94 ${ }^{24}$. It has been also concluded that for advanced FRCs, the critical fiber length could be as much as 50 times the diameter of the fiber. The diameter of microglass fibers used in this study is $6 \mu \mathrm{m}$ and the critical fiber length should be, therefore, around $300 \mu \mathrm{m}$.

Regarding the fracture patterns, the restored groups produced predominantly favorable fracture patterns (i.e. fracture above the CEJ). However, crown specimens that have reinforced core material of SFRC with prefabricated glass fiber post (Group B) revealed some delaminating of PFC from the SFRC substructure layer. This finding is in accordance with previous studies which showed that SFRC core improves the failure mode of restored damaged incisors to be more repairable ${ }^{11,20,21)}$. Results indicated that SFRC substructure supports the PFC layer and serve as a crack prevention and redirection layer. Previous studies demonstrated that mechanism of arresting the crack propagation is greatly influenced by the distance between the SFRC substructure and the surface where the stress initiates ${ }^{36,38)}$. Thus, highly important is how thick SFRC and PFC layers are applied. In laboratory studies it was observed that optimal thickness of the veneering PFC composite over the SFRC substructure is between $1-1.5 \mathrm{~mm}^{36,38)}$.

The results of the present study is in agreement with previous studies with regard to reinforcing effect of fiber post on anterior composite restorations ${ }^{39,40)}$. Whereas others showed that fiber posts do not strengthen the teeth and increase the incidence of catastrophic fractures ${ }^{41,42)}$. Glass fiber posts with a close elastic modulus to dentine improve the stress distribution along the root. The adhesion of fiber posts to the root dentine determines their resistance to dislodgement ${ }^{43)}$. So, the fundamental requirement is to achieve an effective bond among luting materials, composite resin matrix of fiber posts, and root canal dentine by providing high retention. Because of the semi-interpenetrating polymer network (-IPN) polymer matrix structure, the MI glass fiber posts used in this study have good bonding ability with luting material and direct composite core \restorations enabling reliable surface retained applications ${ }^{43}$. This is in accordance with many researchers, who concluded in their studies that the ability of bonding resins to penetrate into fiber post with semi-IPN polymer matrix may give the opportunity to establish a good link between fiber posts, luting cements and composite cores $^{39,40,44,45)}$.

Interestingly, the fracture load of the CAD/CAM composite restorations (Group D) was lower than that of the direct composite restorations reinforced by SFRC or prefabricated glass fiber post (Groups A, B, C). This finding could be explained partially by the difference in brittleness between the direct and indirect composites used in the present study. While the CAD/CAM blocks were well polymerized with photo-curing and heatcuring, the veneered PFC was polymerized by photocuring without heat-curing. Consequently, the $\mathrm{CAD} /$ CAM composite restorations were more brittle than the directly made restorations.

In the literature, the maximum incisal forces of anterior teeth varies, but the amount was most often around $200 \mathrm{~N}$, which is lower than the failure loads of SFRC post-core (Group C) restorations (300 N) found in this study ${ }^{46)}$. Therefore, it may be suggested that anterior teeth with a $2 \mathrm{~mm}$ ferrule, restored with SFRC post-core complex, would resist normal occlusal forces. However, this study did not consider the influence of parafunctional habits such as bruxism.

The question then arises whether the light-cure SFRC material could have an adequate polymerization also inside the root canal. The surface microhardness (VH) of composites could help indirectly to evaluate the degree of the conversion of the monomer at different depth within the same composite ${ }^{23,47)}$. In this study, the maximum $\mathrm{VH}$ of each tested core composites at the $0 \mathrm{~mm}$ depth (top surface layer) was considered as the baseline, which represented the best degree of conversion of each composite. The ratio of $\mathrm{VH}$ at the $10 \mathrm{~mm}$ depth (apical portion) compared with the baseline could be used to judge the polymerization capability of each composite and a ratio above $80 \%$ has often been used as a minimum acceptable threshold value ${ }^{48)}$. Based on this calculated method, flowable light-cure SFRC could be used up to $8 \mathrm{~mm}$ depth in side canal while dual-cure CBC could be used safely up to $10 \mathrm{~mm}$ depth (Fig. 6). This is interesting and could be attributed to the potential light transmitting capacity of the short glass fibers inside the canal as well as the greater transparency observed in SFRC material. This finding is in line with the result of curing depth performed in the study by Shouha and Ellakwa, which showed that SFRC exhibited the deepest cure $(6.7 \mathrm{~mm})$ in comparison with different conventional PFC composites ${ }^{49)}$. Previous studies have also shown that FRCs conduct and scatter the light better than conventional PFC composites ${ }^{47,50)}$.

Several studies have been conducted on the fracture resistance of endodontically treated incisor teeth restored with different esthetic posts including zirconia and fiber posts p $^{9,12,39-42)}$. However, direct comparison of fracture resistance values and failure modes obtained from these studies is improper because of several variations in the study designs such as using human teeth or bovine teeth or artificial teeth, luting procedure of the post, tooth preparation, crown restoration, artificial aging, or loading conditions.

The fracture resistance values determined by the various investigators were recorded under different measurement criteria. These criteria were either initial cracking that was interpreted as crack development or a reduction in the load by an absolute or relative 
amount ${ }^{26,36,40)}$. For this study, the maximum static force on the final fracture was determined. Stress applied to the teeth and dental restorations is generally low and repetitive rather than being isolated and impactive in nature. However, because of a linear relationship between fatigue and static loading, the compressive static test also gives valuable information concerning the fracture behavior and load-bearing capacity ${ }^{31)}$.

It is important to emphasize that a valuable advantage of using flowable SFRC is that it enable restoration of the extensively destroyed tooth using composite, and this approach reduces the number of sessions required to end the restorative procedure as well as the cost of treatment. Further research and clinical trials are needed for detailed information on this flowable SFRC material and to validate this in vitro study.

\section{CONCLUSIONS}

The restoration of structurally compromised incisor teeth with the use of flowable SFRC as core material with regular fiber post displayed promising performance in matter of load bearing capacity and failure mode.

\section{ACKNOWLEDGMENTS}

This study belongs to the research activity of BioCity Turku Biomaterials Research Program (www. biomaterials.utu.fi) and it was supported by Stick Tech Ltd. Member of the GC Group.

\section{CONFLICTS OF INTERESTS}

Authors LL, VO and MF declare to have no conflict of interests. Author PV consults for Stick Tech-Member of the GC Group in R \& D and training. Author SG has received consultancy fees from StickTech/GC.

\section{REFERENCES}

1) Qualtrough AJ, Mannocci F. Tooth-colored post system: a review. Oper Dent 2003; 28: 86-91.

2) Grandini S, Goracci C, Tay FR, Grandini R, Ferrari M. Clinical evaluation of the use of fiber posts and direct resin restorations for endodontically treated teeth. Int $\mathrm{J}$ Prosthodont 2005; 18: 399-404.

3) Figueiredo FE, Santos RC, Silva AS, Valdívia AD, OliveiraNeto LA, Griza S, et al. Ferrule design does not affect the biomechanical behavior of anterior teeth under mechanical fatigue: An in vitro evaluation. Oper Dent 2019; 44: 273-280.

4) Saupe WA, Gluskin AH, Radke RA. A comparative study of fracture resistance between morophological dowel and cores and a resin-reinforced dowel system in the intraradicular restoration of structurally compromised roots. Quintessence Int 1996; 27: 483-491.

5) Sirimai S, Riis DN, Morgano SM. An in vitro study of the fracture resistance and the incidence of vertical root fracture of pulpless teeth restored with post-and-core systems. J Prosthet Dent 1999; 81: 262-269.

6) Fokkinga WA, Kreulen CM, Vallittu PK, Creugers NH. A structured analysis of in vitro failure loads and failure modes of fiber, metal, and ceramic post-and-core systems. Int J
Prosthodont 2004; 17: 476-482.

7) Fokkinga WA, Kreulen CM, LeBell- Rönnlöf AM, Lassila LV, Vallittu PK, Creugers NH. Fracture behavior of structurally compromised non-vital maxillary premolars restored using experimental fiber reinforced composite crowns. Am J Dent 2006; 19: 326-332.

8) Roeters JJ. Extended indications for directly bonded composite restorations: a clinician's view. J Adhes Dent 2001; 3: 81-87.

9) Fraga RC, Chaves BT, Mello GS, Siqueira JF Jr. Fracture resistance of endodontically treated roots after restoration. $\mathrm{J}$ Oral Rehabil 1998; 25: 809-813.

10) Nagata K, Garoushi SK, Vallittu PK, Wakabayashi N, Takahashi H, Lassila LVJ. Fracture behavior of singlestructure fiber-reinforced composite restorations. Acta Biomater Odontol Scand 2016; 2: 118-124.

11) Bijelic J, Garoushi S, Vallittu PK, Lassila LV. Short fiber reinforced composite in restoring severely damaged incisors. Acta Odontol Scand 2013; 71: 1221-1231.

12) Bijelic-Donova J, Garoushi S, Vallittu PK, Lassila LVJ. Mechanical properties, fracture resistance, and fatigue limits of short fiber reinforced dental composite resin. J Prosthet Dent 2016; 115: 95-102.

13) Xu HHK, Quinn JB, Smith DT, Giuseppetti AA, Eichmiller FC. Effect of different whiskers on the reinforcement of dental resin composites. Dent Mater 2003; 19: 359-367.

14) Zandinejad AA, Atai M, Pahlevan A. The effect of ceramic and porous fillers on the mechanical properties of experimental dental composites. Dent Mater 2006; 22: 382-387.

15) Garoushi S, Vallittu PK, Lassila LVJ. Short glass fiber reinforced restorative composite resin with semiinterpenetrating polymer network matrix. Dent Mater 2007; 23: 1356-1362.

16) Garoushi S, Säilynoja E, Vallittu P, Lassila L. Physical properties and depth of cure of a new short fiber reinforced composite. Dent Mater 2013; 29: 835-841.

17) Garoushi S, Vallittu PK, Lassila L. Mechanical properties and wear of five commercial fibre-reinforced filling materials. Chin J Dent Res 2017; 20: 137-143.

18) Garoushi S, Gargoum A, Vallittu PK, Lassila L. Short fiberreinforced composite restorations: A review of the current literature. Investig Clin Dent 2018; 9: e12330.

19) Lassila L, Säilynoja E, Prinssi R, Vallittu P, Garoushi S. Characterization of a new fiber-reinforced flowable composite. Odontology 2019; 107: 342-352.

20) Garoushi S, Vallittu PK, Lassila LV. Direct restoration of severely damaged incisors using short fiber-reinforced composite resin. J Dent 2007; 35: 731-736.

21) Garoushi S, Vallittu PK, Lassila LV. Continuous and short fiber reinforced composite in root post-core system of severely damaged incisors. Open Dent J 2009; 3: 36-41.

22) Forster A, Sáry T, Braunitzer G, Fráter M. In vitro fracture resistance of endodontically treated premolar teeth restored with a direct layered fiber-reinforced composite post and core. J Adhes Sci Technol 2017; 31: 1454-1466.

23) Fráter M, Lassila L, Braunitzer G, Vallittu PK, Garoushi S. Fracture resistance and marginal gap formation of post-core restorations: influence of different fiber reinforced composites. Clin Oral Investig 2019 [Epub ahead of print].

24) Vallittu PK. High-aspect ratio fillers: fiber-reinforced composites and their anisotropic properties. Dent Mater 2015; 31: 1-7.

25) Garoushi S, Vallittu P, Lassila L. Mechanical properties and radiopacity of flowable fiber-reinforced composite. Dent Mater J 2019; 38: 196-202.

26) Quinn JB, Quinn GD. Material properties and fractography of an indirect dental resin composite. Dent Mater 2010;26: 589-599.

27) Ilie N, Hickel R, Valceanu AS, Huth, KC. Fracture toughness of dental restorative materials. Clin Oral Investig 2012; 16 : 
489-498.

28) Heintze SD, Ilie N, Hickel R, Reis A, Loguercio A, Rousson V. Laboratory mechanical parameters of composite resins and their relation to fractures and wear in clinical trials-A systematic review. Dent Mater 2017; 33: 101-114.

29) Fennis WM, Tezvergil A, Kuijs RH, Lassila LV, Kreulen $\mathrm{CM}$, Creugers $\mathrm{NH}$, et al. In vitro fracture resistance of fiber reinforced cusp-replacing composite restorations. Dent Mater 2005; 21: 565-572.

30) Garoushi S, Lassila LVJ, Vallittu PK. Fiber-reinforced composite substructure: load bearing capacity of an onlay restoration. Acta Odontol Scand 2006; 64: 281-285.

31) Garoushi S, Lassila LVJ, Tezvergil A, Vallittu PK. Static and fatigue compression test for particulate filler composite resin with fiber-reinforced composite substructure. Dent Mater 2007; $23: 17-23$.

32) Keulemans F, Lassila LVJ, Garoushi S, Vallittu PK, Kleverlaan CJ, Feilzer AJ. The influence of framework design on the load-bearing capacity of laboratory-made inlayretained fibre-reinforced composite fixed dental prostheses. J Biomech 2009; 42: 844-849.

33) Dere M, Ozcan M, Göhring TN. Marginal quality and fracture strength of root-canal treated mandibular molars with overlay restorations after thermocycling and mechanical loading. J Adhes Dent 2010; 12: 287-294.

34) Keulemans F, Van Dalen A, Kleverlaan CJ, Feilzer AJ. Static and dynamic failure load of fiber-reinforced composite and particulate filler composite cantilever resin-bonded fixed dental prostheses. J Adhes Dent 2010; 12: 207-214.

35) Fráter M, Forster A, Keresztúri M, Braunitzer G, Nagy K. In vitro fracture resistance of molar teeth restored with a short fibre-reinforced composite material. J Dent 2014; 42: 11431145 .

36) Garoushi S, Hatem M, Lassila L, Vallittu PK. The effect of short fiber composite base on microleakage and load bearing capacity of posterior restorations. Acta Biomater Odontol Scand 2015; 1: 6-12.

37) Bijelic-Donova J, Garoushi S, Lassila L, Keulemans F, Vallittu PK. Mechanical and structural characterization of discontinuous fiber-reinforced dental resin composite. J Dent 2016; 52: 70-78.
38) Garoushi S, Lassila LV, Tezvergil A, Vallittu PK. Load bearing capacity of fibre-reinforced and particulate filler composite resin combination. J Dent 2006; 34: 179-184.

39) Le Bell-Rönnlöf AM, Lassila LV, Kangasniemi I, Vallittu PK. Load-bearing capacity of human incisor restored with various fiber-reinforced composite posts. Dent Mater 2011; 27: 107115.

40) Hatta M, Shinya A, Vallittu PK, Shinya A, Lassila LV. High volume individual fiber post versus low volume fiber post: The fracture load of the restored tooth. J Dent 2011; 39: 65-71.

41) Zicari F, Van Meerbeek B, Scotti R, Naert I. Effect of ferrule and post placement on fracture resistance of endodontically treated teeth after fatigue loading. J Dent 2013; 41: 207-215.

42) Lazari PC, de Carvalho MA, Del Bel Cury AA, Magne P. Survival of extensively damaged endodontically treated incisors restored with different types of posts-and-core foundation restoration material. J Prosthet Dent 2018; 119: 769-776.

43) Vallittu PK. Are we misusing fiber posts? Guest editorial. Dent Mater 2016; 32: 125-126.

44) Le Bell AM, Tanner J, Lassila LV, Kangasniemi I, Vallittu P. Bonding of composite resin luting cement to fiber-reinforced composite root canal posts. J Adhes Dent 2004; 6: 319-325.

45) Le Bell AM, Lassila LV, Kangasniemi I, Vallittu PK. Bonding of fibre-reinforced composite post to root canal dentin. J Dent 2005; 33: 533-539.

46) Anusavice KJ. Phillips' science of dental materials. 11th ed. St. Louis: Elsevier; 2003. p. 93-94, 598-603.

47) Garoushi S, Vallittu PK, Lassila LV. Depth of cure and surface microhardness of experimental short fiber-reinforced composite. Acta Odontol Scand 2008; 66: 38-42.

48) Flury S, Hayoz S, Peutzfeldt A, Hüsler J, Lussi A. Depth of cure of resin composites: is the ISO 4049 method suitable for bulk fill materials. Dent Mater 2012; 28: 521-528.

49) Shouha PSR, Ellakwa AE. Effect of short glass fibers on the polymerization shrinkage stress of dental composite. J Biomed Mater Res B Appl Biomater 2017; 105: 1930-1937.

50) Le Bell AM, Tanner J, Lassila LV, Kangsniemi I, Vallittu PK. Depth of light-initiated polymerization of glass fiber-reinforced composite in a simulated root canal. Int J Prosthodont 2003; 4: 403-408. 